\title{
Application of project management methods in the Czech Republic
}

\author{
Pavel Taraba ${ }^{1}$ \\ ${ }^{1}$ Tomas Bata University in Zlín, nám. T. G. Masaryka 5555, 76001 Zlín, Czech Republic
}

\begin{abstract}
The paper aims to determine the level of application of project management methods in the Czech Republic. In the first part, selected project management methods based on an analysis of available information resources specifically regarding the Czech Republic are defined. The main theoretical background of the paper is based on documents issued by the International Project Management Association (IPMA) and the Project Management Institute (PMI). With the use of a questionnaire survey, the level of application of project management methods in organizations operating in the Czech Republic was assessed. The questionnaire survey was conducted in three stages, the first carried out in 2015, the second in 2016, and the final stage in 2017. Based on a comparison of the results of the individual analyses, it is possible to describe the development of the application of the project management methods over time.
\end{abstract}

\section{Introduction}

Considering the application of project management methods, the situation has changed greatly over the past fifteen years. The separate parts of this article are dedicated to the Project Management definition, Certification of Project Managers in the Czech Republic, Project Management Methods, and Software in the Project Management.

According to Doležal et al. [1], project management indicates a set of standards, recommendations and the most suitable practices possible, all of which describe how to manage the project in the most efficient and productive way. According to Project Management Institute (PMI) [2], project management is the application of knowledge, skills, tools, and technologies to tasks so that they fully meet the requirements of the project. In order to meet the specific objectives of the project, the main trade-offs must be defined [3]. Most of the trade-offs are resolved if the organization's strategy is well understood and trade-offs are discussed during the planning, budgeting and scheduling phases of the project [4]. Larson and Gray [5] define three main tradeoffs as Cost, Time and Scope. Each project must have a clear purpose. The goal of the project should be Specific, Measurable, Achievable/Acceptable, Realistic/Relevant Time Specific/Trackable (SMART), and it should also contain unique features regarding time, the project team, and the service/product. [6]

Time - Each project is defined by time. As part of the project scheduling, network analysis methods are used (for instance the Critical Path Method - CMP or Program Evaluation and Review Technique - PERT).

Cost - Each project needs resources, whether human, financial or material. Cost represents the manifestation of resources used in the time distribution. These three variables are always interdependent [1], [7].

Scope - This aspect represents the unique goal of the project. [5]

The project follows specific phases, the understanding of which allows project managers to more efficiently control the project. According to some definitions, the project phases include a beginning and end stage, and in between which it goes through several phases, which we know as the life cycle of the project. It is important to realize that the life cycle may be different for individual projects. According to IPMA (International Project Management Association) [8], the project has three stages: the pre-project phase, project phase, and post-project phase. In the pre-project phase, the feasibility of project goals is assessed, various analyses are conducted, and studies are processed (for instance an Opportunity Study or Feasibility Study). The project phase includes project start-up, project preparation, project implementation and project closeout. In the post-project phase, the overall evaluation of the project is conducted. However, according to Doležal, Lacko, and Máchal [9] is this final phase often underestimated and neglected. Various terminologies are used regarding project phases, for example, Sweeney and Stark [10] have named individual stages: project imitation, project planning, project execution and finally project monitoring and controlling. According to Burke [11], there are four different project phases: project feasibility, project definition, project execution and project commissioning and handover. 


\subsection{Certification of project managers in the Czech Republic}

Certificates can be obtained in the project management area within the Czech Republic. International Project Management Association [8] offers four certificates according to project manager level of competences: Level D (Certified Project Management Associate), Level C (Certified Project Manager), Level B (Certified Senior Project Manager), Level A (Certified Project Director). On the other hand, the Project Management Institute offers the basic certificates CAMP (Certified Associate in Project Management) and PMP (Project Management Professional). Four other certificates are issued by PMI in association with levels and specializations of project management: PMI-SP (PMI Scheduling Professional), PMI-RMP (PMI Risk Management Professional), PgMP (Program Management Professional), PMI-ACP (PMI Agile Certified Practitioner) [12].

\subsection{Project Management Methods}

According to Kerzner [3], project management methodologies based upon somewhat rigid policies and procedures were created because management organizations sought to achieve standardization in the way that projects were planned scheduled, and controlled. In this paper project management methods are defined based on the Individual Competence Baseline ICB version 4.0 [14] (a modification of version 3.2 [13]) as well as the PMBOK ${ }^{\circledR}$ Guide to Project Management $6^{\text {th }}$ Edition [2].

\subsubsection{ICB version 4.0}

The IPMA Individual Competence Baseline ICB version 4.0 [8] consists of three areas: people competences, practice competences and perspective competences.

The area of people competences includes the personal and interpersonal abilities required to participate in or lead the project successfully. The application of project management methods based on the practice competences pillar is used in a project to realize its success. The methods used in the perspective competences area represent ways in which individuals interact with an environment.

From the present author's point of view, project management methods are encompassed in all three of these areas, with practice competences particularly highlighted. Project managers and project team members have applied for instance scheduling methods (Gantt charts, network diagrams), cost estimating techniques (single or multi-expert estimation, historical data, analogies), methods for monitoring and controlling, resource allocation methods, procurement methods as well as risk management methods, e.g. [14].

\subsubsection{PMBOK® Guide $6^{\text {th }}$ Edition}

The body of knowledge included in the Project Management Institute's PMBOK ${ }^{\circledR}[2]$ includes proven traditional methods that are widely applied as well as innovative techniques and practices that are emerging in the project management area. According to the PMBOK ${ }^{\circledR}$ [2], project managers and project team members have applied various methods: monitoring and reporting methods, scheduling methods (iterative scheduling with backlog, on-demand schedule), costs estimating methods (parametric estimating, three-point estimating, bottom-up estimating, data analysis), reporting methods, quality improvement methods, risk management methods as well as problem-solving methods.

\subsection{Software in Project Management}

When applying specific project management methods, either open source software or paid software can be used. Open source is free software for public use without any financial costs. Most of these programs tend to be more straightforward and have fewer features than paid programs, which is more sophisticated and user friendly. In managing projects, often open source programs can be quite sufficient for small projects. It is often possible to test software applications for a trial period, as limited access opportunities are often offered to a potential buyer. Use of the application during these trial periods usually includes essential functions that are sufficient to verify user acceptance, but often features that make work much easier can be accessed in the paid version only. [15]

In applying project methods, Project Libre (formal OpenProj) is the most commonly used project management Open Source software in the Czech Republic. Most often the paid software used in project management are the programs MS Project (Microsoft) and Primavera (Oracle). The specific product depends on conditions and considerations evaluated by the top management of the organization. Companies implement the same project management software as their parent organization (e.g., US companies often use Primavera software). Other software products that are used by companies in the Czech Republic to manage projects are GanttProject, Easy Project, Projektově.cz, Basecamp, GroupCamp and Merlin.

The main aim of the paper is to evaluate the application of project management methods in the Czech Republic. The main aim of the paper is divided into two separate objectives. The first objective is to find out an answer for the research question: Are the methods of project management applied in most of the surveyed companies at a "very high" or at a "high" level? The second objective is to find out an answer for the research question: Is it possible to observe a growing trend in the application of project management methods in the period 2015-2017 in the surveyed companies? Several organizations in the Czech Republic deal with project management issues, the best known of which are the International Project Management Association (IPMA Czech Republic) and the Project Management Institute 
(PMI - Czech Chapter). IPMA - Czech Republic was formally known as SPŘ (Společnost pro projektové řízení - until 2017). In the paper were defined project management and methods of project management according to Czech [1], [7] [9], [14] and foreign authorities [3],[4] [5], [6] [10], [11], [15] of project management, IPMA [8], [13] and PMI [2], [12]. The use of project management software products along with high-quality databases can lead to more accurate project management forecasts as well as time and cost simulations, using, e.g., the Monte Carlo method.

\section{Research design and Methodology}

The aim of the present survey study was to evaluate the application of project management methods in the Czech Republic.

Two research questions were formulated. 1) Are the methods of project management applied in most of the surveyed companies at a "very high" or at a "high" level? 2) Is it possible to observe a growing trend in the application of project management methods in the period 2015-2017 in the surveyed companies?

To fulfil the first objective of paper, statistical hypothesis was defined (hypothesis having a null and alternative version):

H10: The majority of respondents are not convinced that the methods of project management are applied in most of the surveyed companies at a "very high" or at a "high" level.

H1A: The majority of respondents are convinced that the methods of project management are applied in most of the surveyed companies at a "very high" or at a "high" level.

This hypothesis was tested at significance level pvalue 0.05 by statistical tools XL statistics and MedCalc Software. We assumed that methods of project management would be applied in most of the surveyed companies at the designated very high or on the high level.

To fulfil the second objective of paper, means cooperation by statistical software SPSS was conducted. Also, we assumed that it would be possible to observe a growing trend in the application of project management methods in the period 2015-2017 in the surveyed companies. All of the surveyed companies are located within the territory of the Czech Republic.

The questionnaire survey was conducted in three stages (in 2015, in 2016 and 2017). The questionnaire was sent by post or by e-mail. The research set of stage 1 (2015) consisted of 165 respondents. These respondents were selected on a random basis. The number of received questionnaires was 36 , i.e., the return rate was $21.82 \%$. The research set of stage 2 (2016) consisted of 165 respondents which were also selected on a random basis. The number of received questionnaires was 48 , i.e., the return rate was $29.09 \%$. In Stage 3 (2017), the research set also consisted of 165 respondents selected on a random basis. The number of received questionnaires was 22 , i.e., the return rate was $13.33 \%$. A five-point Likert scale was used to describe the level of application of project management methods in the Czech Republic (1 - very high level, 2 - high level, 3 medium level, 4 - low level, 5 - very low level).

Data from the questionnaires were processed in Microsoft Excel and SPSS (histograms). Subsequently, statistical tests were performed using the tools XL statistics (X2) and MedCalc Software (z-test). The Chisquared statistic is the sum of the squares of the differences of the observed and expected frequency divided by the expected frequency for every cell [16]. Computational notes of the P-value defined the significance level, with the P-value calculated using a general z-test according to Altman [17] and Fleiss et al. [18]

In the conclusion of the present paper, the level of application of project management methods in the Czech Republic is described.

\section{Results}

Here the level of application project management methods in the years 2015-2017 will be analysed. In the first stage of the survey carried out in $2015,8.3 \%$ of the respondents stated that the level of application project management methods was very high and $19.4 \%$ respondents indicated that it was high. $38.9 \%$ of the respondents considered the level of application project management methods as being at a "medium" level, and $35.4 \%$ of respondents considered this level at their organization as "low" or "very low" (Table 1.).

Table 1. The level of application of PM methods (2015) [author].

\begin{tabular}{|c|c|c|c|}
\hline & Frequency & Percent & $\begin{array}{c}\text { Cumulative } \\
\text { Percent }\end{array}$ \\
\hline Very high level & 3 & 8,3 & 8,3 \\
\hline High level & 7 & 19,4 & 27,8 \\
\hline Medium level & 14 & 38,9 & 66,7 \\
\hline Low level & 6 & 16,7 & 83,3 \\
\hline Very low level & 6 & 16,7 & 100,0 \\
\hline Total & $\mathbf{3 6}$ & $\mathbf{1 0 0 , 0}$ & \\
\hline
\end{tabular}

The following figure 1 depicts a histogram showing the numbers of respondents at the specific level of application project management methods in 2015 .

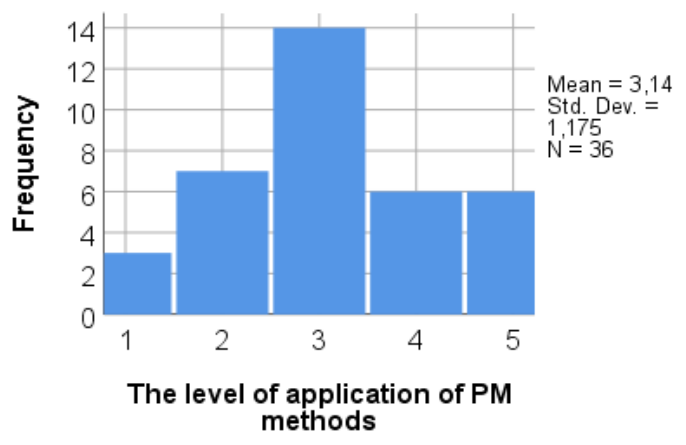

Fig. 1. Histogram - The level of application Project Management methods (2015) [author]. 
It is positive that in the second stage of the survey carried out in 2016, $43.8 \%$ of the respondents considered the level of application project management methods as very high or high. $31.3 \%$ of the respondents considered this level as medium and $8.3 \%$ as low. A very low level of application of project management methods, as in the stage 1 survey, was identified by $16.7 \%$ of the respondents (Table 2.).

Table 2. The level of application of PM methods (2016) [author].

\begin{tabular}{|c|c|c|c|}
\hline & Frequency & Percent & $\begin{array}{c}\text { Cumulative } \\
\text { Percent }\end{array}$ \\
\hline Very high level & 9 & 18,8 & 18,8 \\
\hline High level & 12 & 25,0 & 43,8 \\
\hline Medium level & 15 & 31,3 & 75,0 \\
\hline Low level & 4 & 8,3 & 83,3 \\
\hline Very low level & 8 & 16,7 & 100,0 \\
\hline Total & $\mathbf{4 8}$ & $\mathbf{1 0 0 , 0}$ & \\
\hline
\end{tabular}

The following figure 2 depicts a histogram showing the numbers of respondents at the specific level of application project management methods in 2016.

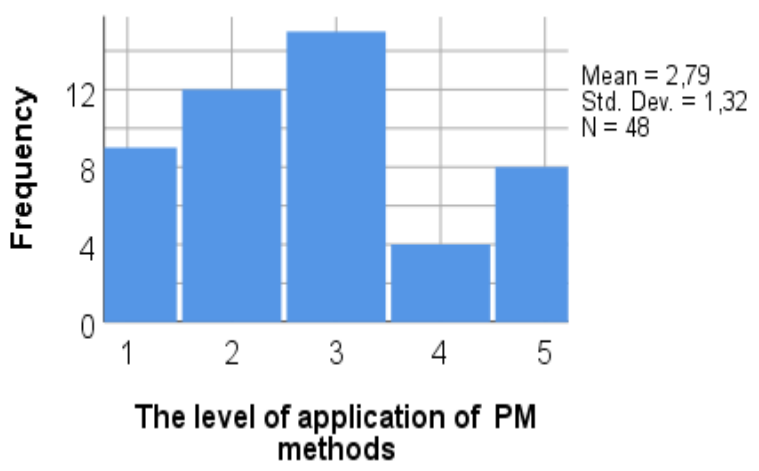

Fig. 2. Histogram - The level of application Project Management methods (2016) [author].

In the third stage of the survey, $36.4 \%$ of the respondents considered the level of application project management methods as very high or high. Up to $40.9 \%$ of the respondents considered this level as medium. It is positive that only $4.5 \%$ respondents stated that the level of application of project management methods was very low (Table 3.)

Table 3. The level of application PM methods (2017) [author].

\begin{tabular}{|c|c|c|c|}
\hline & Frequency & Percent & $\begin{array}{c}\text { Cumulative } \\
\text { Percent }\end{array}$ \\
\hline Very high level & 3 & 13,6 & 13,6 \\
\hline High level & 5 & 22,7 & 36,4 \\
\hline Medium level & 9 & 40,9 & 77,3 \\
\hline Low level & 4 & 18,2 & 95,5 \\
\hline Very low level & 1 & 4,5 & 100,0 \\
\hline Total & $\mathbf{2 2}$ & $\mathbf{1 0 0 , 0}$ & \\
\hline
\end{tabular}

The following figure 3 depicts a histogram showing the numbers of respondents at the specific level of application project management methods in 2017.

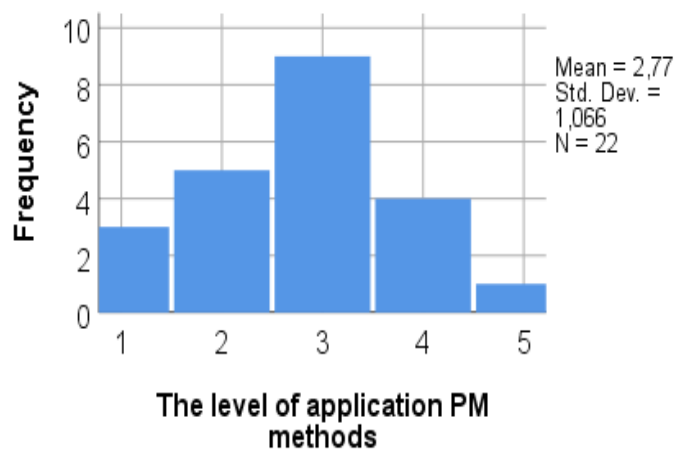

Fig. 3. Histogram - The level of application Project Management methods (2017) [author].

The following figure 4 depicts a histogram showing the numbers of respondents at the specific level of application project management methods $(1-$ very high level, 2 - high level, 3 - medium level, 4 - low level, 5 very low level) between 2015 and 2017.

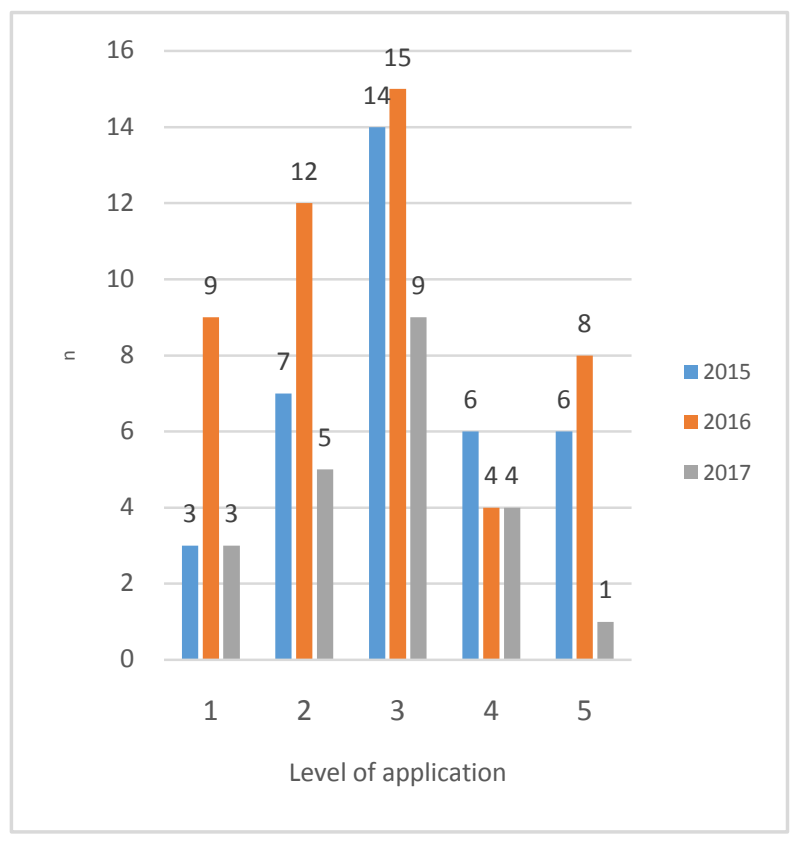

Fig. 4. Histogram - The level of application Project Management methods (2015 - 2017) [author].

Before the hypothesis (H1) was tested, two groups were defined. The first group involved respondents who were convinced that the methods of project management were applied in most of the surveyed companies at a very high or at a high level. The second group involved respondents who were convinced that the methods of project management were applied in most of the surveyed companies at a medium, a low or a very low level. Considering the selected years provide more detailed insights (Table 4): 
Table 4. Two groups of respondents [author].

\begin{tabular}{|c|c|c|c|c|}
\hline & \multicolumn{2}{|c|}{ Frequency } & \multicolumn{2}{c|}{ Percent } \\
\hline & $\begin{array}{c}\text { Very } \\
\text { high } \\
\text { level and } \\
\text { high } \\
\text { level }\end{array}$ & $\begin{array}{c}\text { Medium } \\
\text { level, low } \\
\text { and very } \\
\text { low level }\end{array}$ & $\begin{array}{c}\text { Very } \\
\text { high } \\
\text { level and } \\
\text { high } \\
\text { level }\end{array}$ & $\begin{array}{c}\text { Medium } \\
\text { level, low } \\
\text { and very } \\
\text { low level }\end{array}$ \\
\hline $\mathbf{2 0 1 5}$ & 10 & 26 & 0.28 & 0.72 \\
\hline $\mathbf{2 0 1 6}$ & 21 & 27 & 0.44 & 0.56 \\
\hline $\mathbf{2 0 1 7}$ & 8 & 14 & 0.36 & 0.64 \\
\hline Total & $\mathbf{3 9}$ & $\mathbf{6 7}$ & $\mathbf{0 . 3 7}$ & $\mathbf{0 . 6 3}$ \\
\hline
\end{tabular}

Based on data set 2015, the mean value $\mathrm{h}_{2015}$ was calculated $\left(\mathrm{h}_{2015}=3.14\right)$, based on data set 2016 , the mean value $\mathrm{h}_{2016}$ was calculated $\left(\mathrm{h}_{2016}=2.79\right)$, and based on data set 2017 the mean value $\mathrm{h}_{2017}$ was 2.77 (Figure 2).

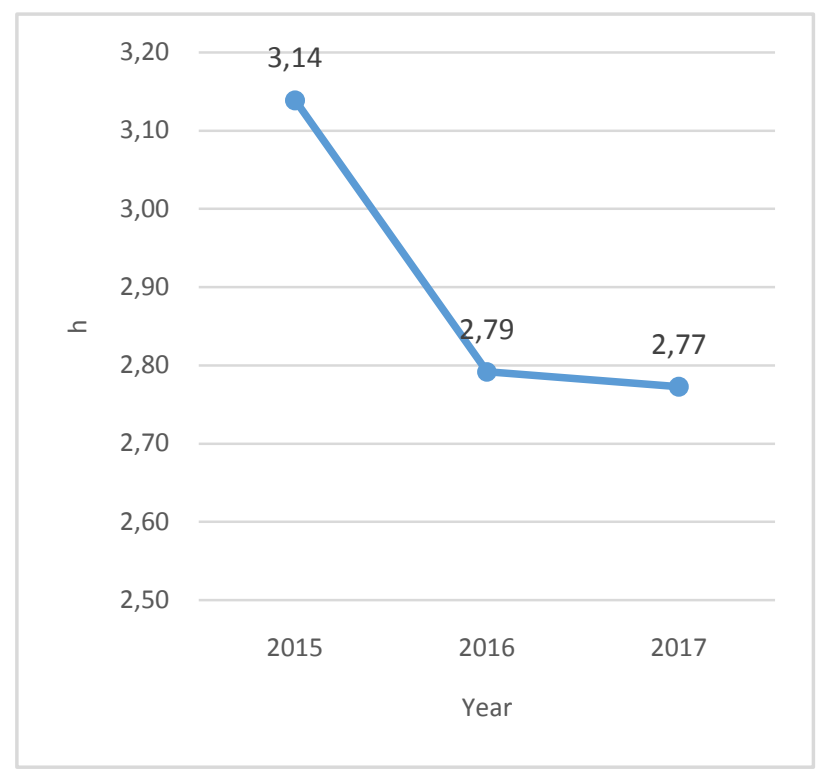

Fig. 5. Mean value $\mathrm{h}$ - The level of application of project management methods $(2015$ - 2017) [author].

Based on figure 5 , it can be assumed that the mean value $h$ is gradually decreasing, which indicates that the level of application of project management methods is gradually increasing (3 - medium level, 2 - high level of application of project management methods). In 2016 there was a year-on-year decline of 0.35 points, and in 2017 there was a year-on-year decline of 0.02 points.

\section{Conclusion}

In answering the research questions, the potential benefits of increasing the level of application of project management methods in the Czech Republic can be formulated. Possible directions for future research will be outlined as well.
It was not possible to respond positively to the first research question. The proportions for each group in total were calculated (Very high or and high level $=0.37$; Medium, low and very low level=0.63). ). Using XL statistics software, the $\mathrm{p}$-value $=0.996732$ was calculated along with Confidence Intervals for p-value (Level=0.95): $\quad \mathrm{ME}=0.092874$; $\quad$ Lower $=0.275051$; Upper $=0.460798$. In MedCalc Software the test for one proportion was calculated as follows: Z-statistics 1.661; significance level P $>0.05 ; 95 \%$ Confidence Intervals of observed proportion $=21.88$ to 53.63 . Based on the test of hypothesis, $\mathrm{H} 10$ is confirmed and $\mathrm{H} 1 \mathrm{~A}$ rejected. As a result of the calculations the null hypothesis is confirmed and therefore it cannot be stated that: The majority of respondents are convinced that the methods of project management are applied in most of the surveyed companies at a "very high" or at a "high" level. Even at stage one $(2015,2016$ nor 2017) of the survey, the level of application of project management methods in most of the surveyed companies (more than $50 \%$ of those surveyed) was not at the "very high" or at the "high" level. Based on data set 2015, the figure was only $28 \%$, based on data set 2016 it was $44 \%$ and based on data set 2017 it was $36 \%$ (Table 4).

The second research question can be answered positively. It is possible to observe a positive trend regarding the increasing application of project management methods in the period 2015-2017 in surveyed companies. This finding is evidenced by a decreasing level of mean value $\mathrm{h}\left(\mathrm{h}_{2015}=3.14, \mathrm{~h}_{2016}=\right.$ 2.79 and $\left.\mathrm{h}_{2017}=2.77\right)$. Considering the standard deviation and standard deviation error of means provide more detailed insights (Table 5)

Table 5. The level of application of project management methods (2015 - 2017) - detailed insights [author].

\begin{tabular}{|c|c|c|c|}
\hline & $\mathbf{2 0 1 5}$ & $\mathbf{2 0 1 6}$ & $\mathbf{2 0 1 7}$ \\
\hline $\mathbf{N}$ & 36 & 48 & 22 \\
\hline Mean (h) & 3.14 & 2.79 & 2.77 \\
\hline Std. Deviation & 1.175 & 1.320 & 1.066 \\
\hline $\begin{array}{c}\text { Std. Error of } \\
\text { Mean }\end{array}$ & 0.196 & 0.191 & 0.227 \\
\hline
\end{tabular}

Identifying possible causes for the increase in the of application project management methods was not, however, the ultimate goal of the present paper. This identification and a subsequent description will be conducted as a part of further research. Nevertheless, to make perfunctory predictions about possible causes, we may refer to the more frequent use of software products (such as MS Project or Oracle Primavera) in the Czech Republic. Within the framework of further research, statistical methods will be used to generalize the results, and the data set for 2018 will be added. Subsequently, more trends regarding the development of the level of application of project management methods in the forthcoming years will be determined. 
This research was supported by Institutional support research program of Tomas Bata University in Zlín: Logistics and Project Management - RO 21181002025.

\section{References}

1. J. Doležal, Project management: a comprehensive, practically and according to international standards (2016)

2. Project Management Institute, $A$ Guide to the Project Management Body of Knowledge (2017)

3. H. Kerzner, Project management: a systems approach to planning, scheduling, and controlling (2013)

4. J. R. Meredith, Project management in practice (2014)

5. W. E. Larson, F. G. Clifford, Project management: the managerial process (2014)

6. H. Maylor, Project Management (2010)

7. A. Svozilová, Project management: system approach to project management (2016)

8. International Project Management Association, Individual competence baseline for project, programme and portfolio management (2015)

9. J. Doležal, P. Máchal, and B. Lacko, Project management according to IPMA (2012)

10. E. Stark, B. Sweeney, Project management for beginners: proven project management methods to complete projects with time \& money to spare (2015)

11. R. Burke, Project management: planning and control techniques (2013)

12. Project Management Institute, Project Manager Competency Development (PMCD) Framework (2007)

13. SPǨ, National standard of project management competence (2012)

14. P. Taraba, M. Hart, and K. Pitrova, Polish J. Manag. Stud. 13, 1 (2016)

15. K. Schwalbe, Project management in IT: complete guide (2011)

16. I. Campbell, Chi-squared and Fisher-Irwin tests of two-by-two tables with small sample recommendations. Statistics in Medicine, 26,19 (2007)

17. D. G. Altman, Practical statistics for medical research. CRC press. (1990)

18. J. L. Fleiss, B. Levin and M. C. Paik, The measurement of interrater agreement. John Wiley \& Sons, Inc. (2004) 